\title{
Computer aided FEA simulation of EN45A parabolic leaf spring
}

\author{
Krishan Kumar $^{\mathrm{a}^{*}}$ and M. L. Aggarwal ${ }^{\mathrm{b}}$
}

${ }^{a}$ Assistant Professor, Deptt. Of Mechanical Engineering, YMCA University of Science \& Technology, Faridabad, (HR.), India

${ }^{b}$ Professor, Deptt. Of Mechanical Engineering, YMCA University of Science \& Technology, Faridabad, (HR.), India

\section{H R O N I C L E A B S T R A C T}

Article history:

Received September 252012

Received in revised format

December 282012

Accepted January25 2013

Available online

25January 2013

Keywords:

Parabolic

Leaf Spring

$C A D$

FEA

EN45A

\begin{abstract}
This paper describes computer aided finite element analysis of parabolic leaf spring. The present work is an improvement in design of EN45A parabolic leaf spring used by a light commercial automotive vehicle. Development of a leaf spring is a long process which requires lots of test to validate the design and manufacturing variables. A three-layer parabolic leaf spring of EN45A has been taken for this work. The thickness of leaves varies from center to the outer side following a parabolic pattern. These leaf springs are designed to become lighter, but also provide a much improved ride to the vehicle through a reduction on interleaf friction. The CAD modeling of parabolic leaf spring has been done in CATIA V5 and for analysis the model is imported in ANSYS-11 workbench. The finite element analysis (FEA) of the leaf spring has been carried out by initially discretizing the model into finite number of elements and nodes and then applying the necessary boundary conditions. Maximum displacement, directional displacement, equivalent stress and weight of the assembly are the output targets of this analysis for comparison \& validation of the work.
\end{abstract}

\section{Introduction}

Leaf springs are the components of the suspension system. They perform isolation task in transferring vibration due to road irregularities to driver's body.Increasing competition and innovations in automobile sector tends to modify the existing products or replacing old products by new and advanced material products. More efforts are taken in order to increase the comfort of user. To improve the suspension system, many modifications have taken place over the time. Inventions of parabolic leaf spring and use of composite materials for these springs are some of these latest modifications in suspension systems. The main advantages of parabolic leaf springs are that they are lighter, cheaper, better fatigue life, and they isolate more noise. CAE tools are widely used in the automotive industries. In fact, their use has enabled the automakers to reduce product development cost and time while improving the safety, comfort, and durability of the vehicles they produce. Aggarwal and Chawla (2007)described that fretting fatigue between leaves can be reduced by careful control of shot peening parameters. The bending strength of EN45A parabolic leaf spring is found to be higher as compared with semi-elliptic leaf spring.Kanbolat and Soner(2011)used a numerical approach to obtain the fatigue

* Corresponding author. Tel: +919896596710

E-mail: er.krishanverma@yahoo.com( K. Kumar)

(c) 2013 Growing Science Ltd. All rights reserved. doi: $10.5267 / j . j$ jiec.2013.01.005 
life and the leaf geometry against the environmental condition on the base of material properties. This work presents a more precise method based on non-linear finite element solutions by evaluating the effects of the production parameters, the geometrical tolerances and the variations in the characteristics of the material. Ahmad Refngahet al. (2009)explained fatigue life prediction based on finite element analysis and variable amplitude loading (VAL). Service loading of parabolic spring has been collected using data acquisition system. Finite element analysis (FEA) was performed on the spring model so stress and damage distribution can be observed. Experimental works was done in order to validate the FEA result. Patnaik et al. (2012b) carried out on a parabolic leaf spring of a mini loader truck. The spring has been analyzed by applying load and the corresponding values of stress and displacement are computed. Camber and Leaf span of a Parabolic Leaf Spring was found for Optimized Stress and Displacement value using Artificial Neural Networks.Patnaik et al. (2012b) worked on a mono parabolic leaf spring. The modeling of the leaf spring has been done in CATIA V5 R20. In order to study the behavior of parabolic leaf spring Design of experiments has been implemented. In DOE, input parameters such as Eye Distance \& Depth of camber have been varied and their effects on output parameters have been plotted. Soner et al.(2011) took a five-layer parabolic leaf spring, optimized it based on material, geometric design improvement, nonlinear finite element analyze calculations regarding boundary conditions of leaf spring. The finite element model of the new design has been generated by decreasing weight through removing layers at the same boundary conditions and evaluations have been made in comparison with the first design.Yadav et al. (2012)analyzed a leaf spring whose thickness varies from the center to the outer side following a parabolic pattern. Initially the magnitude of stress pertaining to parabolic leaf spring is computed by finite element method and then the approach to minimizing the stress has been carried out effectively with help of Local Algorithm for Constants and Priorities. Jayaswal and Kushwah (2012) discussed practical means of facilitating participatory steps taken in productivity enhancement with the emphasis on rejection minimization programs in parabolic Leaf Spring Manufacturing Unit in India. In this work, various approaches and efforts made for productivity improvement were discussed with the emphasis on reduction of rejections in terms of End Gap and Camber Less in leaf spring in Parabolic Leaf Spring Manufacturing. Dewangan et al. (2012)described basic structure, stress characteristics, engineering finite element modeling for analyzing \& high stress zones. The equivalent von-misses stresses are plotted for the parabolic leaf spring. Abdullah et al. (2008)presented about fatigue life prediction based on finite element analysis and variable amplitude loading (VAL). Service loading of parabolic spring has been collected using data acquisition system. Finite element analysis (FEA) was performed on the spring model so stress and damage distribution can be observed. Experimental works was done in order to validate the FEA result. Though, a lot of work had been done on conventional leaf springs but systematic design of parabolic leaf springs using CAD methodologies is not available in literature. The objective of present work is to analyze a three layer parabolic leaf spring as shown in Fig. 1 by using CAE tools. This design is characterized by fewer leaves whose thickness varies from center to ends following a parabolic pattern. In this design, interleaf friction is unwanted, therefore only contact between the leaves at the ends and at the centeris provided with the help of rubber tip inserts and rubber pads respectively. The main focus is on validation of the model by considering displacement, equivalent stress and weight of the parabolic leaf spring assembly.

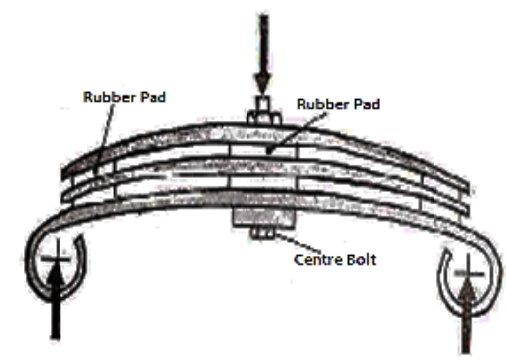

Fig. 1. Parabolic Leaf Spring Assembly 


\section{Design \& Analysis}

\subsection{CAD Modeling}

CAD modeling software is dedicated for the specialized job of 3D-modeling. The model of the multi leaf spring structures also includes many complicated parts, which are difficult to make by any of other CAD modeling as well as Finite Element software. The Chemical composition of EN45A spring steel by \% weight is $0.61 \mathrm{C}, 1.8 \mathrm{Si}, 0.79 \mathrm{Mn}, 0.02 \mathrm{~S}, 0.024 \mathrm{P}$ and geometrical specification of leaf springs are; Span length $=940 \mathrm{~mm}$, Seat Length $=100 \mathrm{~mm}$, Number of leaf $=3$, Rated load $=3600 \mathrm{~N}$, Maximum Load $=7600 \mathrm{~N}$, Width of leaf $=60 \mathrm{~mm}$, Tip Inserts: $50 \mathrm{~mm}$ Diameter, Centre Rubber Pad $=100 \mathrm{mmX} 50 \mathrm{mmX} 5 \mathrm{~mm}$

\section{Table 1}

Thickness of leaves

\begin{tabular}{ccc}
\hline S.N. & Thickness at Centre & Thickness at Edge \\
\hline Main Leaf & $8 \mathrm{~mm}$ & $6 \mathrm{~mm}$ \\
$2^{\text {nd }}$ Leaf & $8 \mathrm{~mm}$ & $5 \mathrm{~mm}$ \\
$3^{\text {rd }}$ Leaf & $8 \mathrm{~mm}$ & $3 \mathrm{~mm}$ \\
\hline
\end{tabular}

CATIA software is having special tools in generating surface design to construct typical surfaces, which are later converted into solid models. Solid model of all parts of the structures are then assembled to make a complete structure. The process of assembly is very much analogous to general process of fabricating structures while real production. According to above mentioned dimensions \& specifications the CAD model of the parabolic leaf spring has been modeled in CATIA software as shown in Fig. 2 to Fig. 5 as follows,

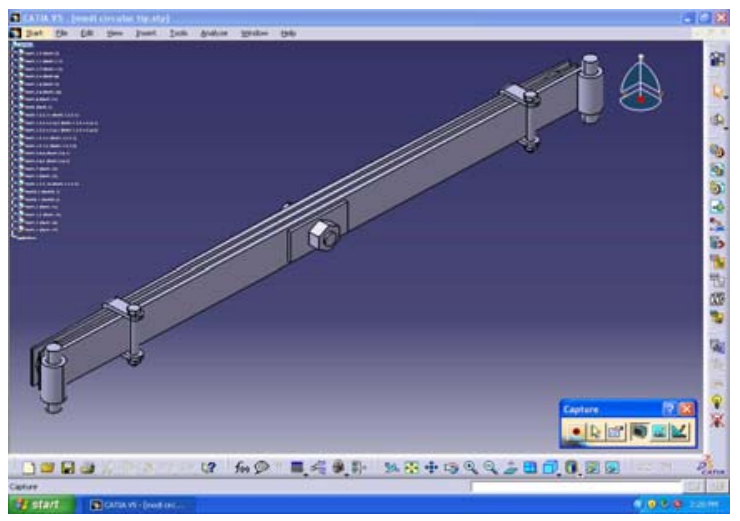

Fig. 2 CAD Model of Parabolic Leaf Spring

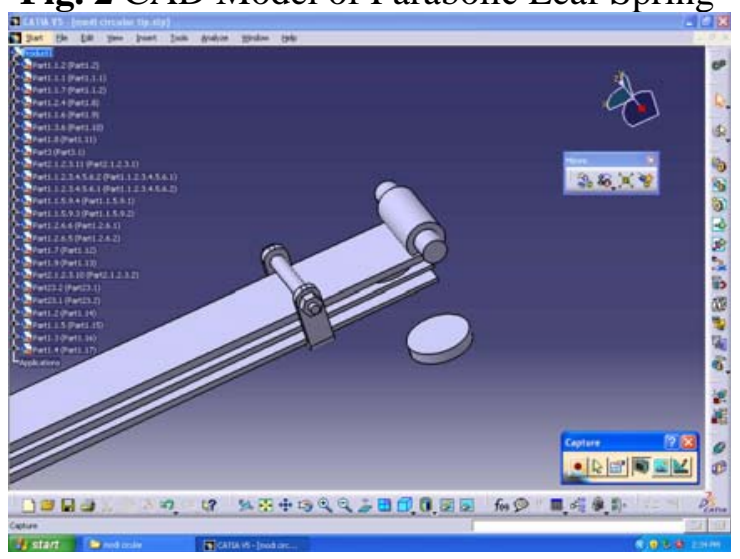

Fig. 4. Assembly of Circular Tip Inserts

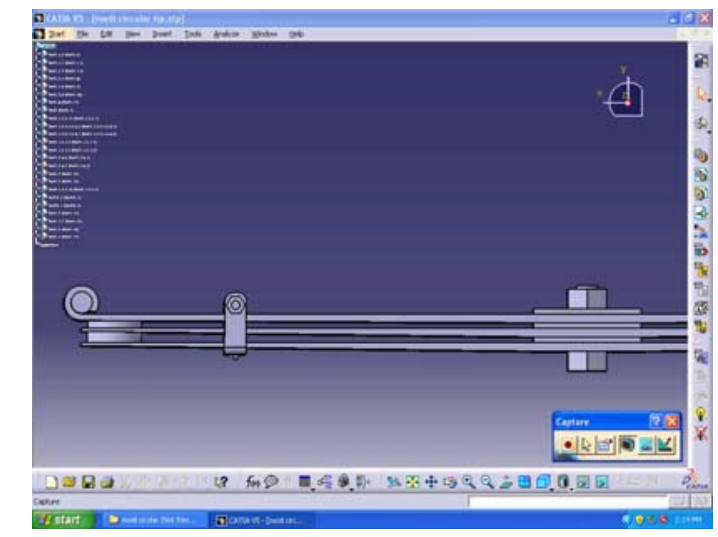

Fig. 3. Taper Leaves of Assembly

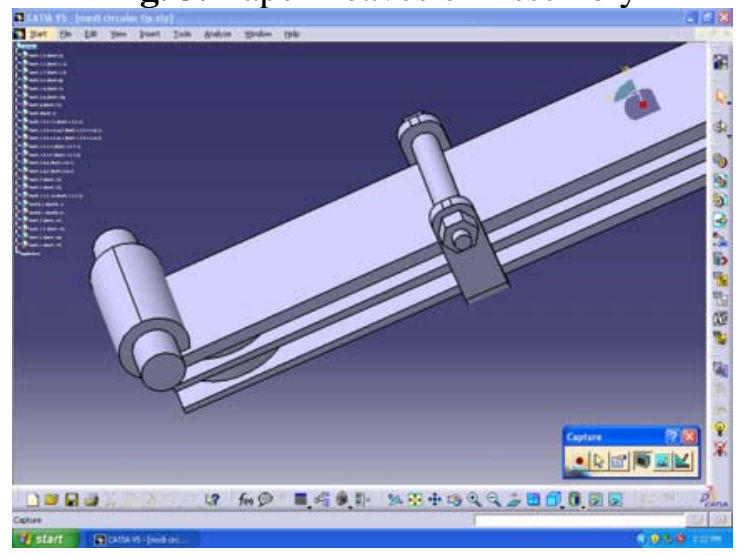

Fig. 5. Eye end of main Leaf 
A stress-deflection analysis is performed using finite element analysis (FEA). The complete procedure of analysis has been done using ANSYS-11. The CAD model of parabolic leaf spring is imported to ANSYS-11 workbench as shown in Figure-6 below.

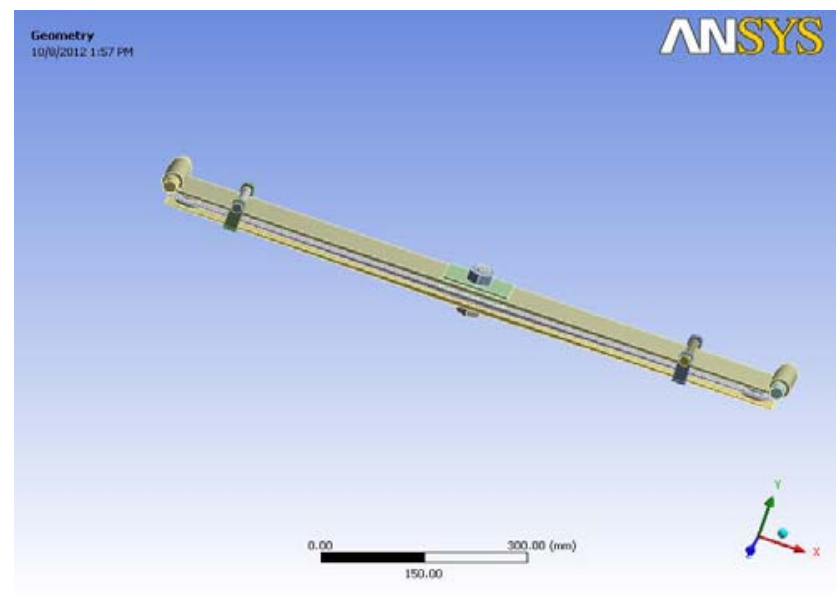

Fig. 6. Model in ANSYS-11 Workbench

To conduct finite element analysis, the general process of FEA is divided into three main phases, preprocessor, solution, and postprocessor.

\subsubsection{Preprocessor}

The preprocessor is a program that processes the input data to produce the output that is used as input to the subsequent phase (solution). Following are the input data that needs to be given to the preprocessor: 1.Type of analysis 2.Element type 3.Real constants 4.Material properties 5.Geometric model 6. Meshed model 7.Loading and boundary conditions.

\subsubsection{Solution}

Solution phase is completely automatic. The FEA software generates the element matrices, computes nodal values and derivatives, and stores the result data in files. These files are further used by the subsequent phase (postprocessor) to review and analyze the results through the graphic display and tabular listings.

\subsubsection{Postprocessor}

The output from the solution phase is in the numerical form and consists of nodal values of the field variable and its derivatives. For example, in structural analysis, the output is nodal displacement and stress in the elements. The postprocessor processes the result data and displays them in graphical form to check or analyze the result. The graphical output gives the detailed information about the required result data.

Table 2 shows different parameters associated with material properties.Meshing of the model is done in which model is discretized into finite number of elements and nodes. This mesh along with material properties is used to mathematically represent the stiffness and mass distribution of the structure.As already discussed about parabolic leaf springs that rubber tip inserts has been provided between the leaves. 
Table 2

Material properties of EN45A spring steel

\begin{tabular}{ll}
\hline Parameter & Value \\
\hline Material selected- steel & EN45A \\
Young's Modulus, E & $2.1^{*} 10^{5} \mathrm{~N} / \mathrm{mm}^{2}$ \\
Poisson's Ratio & 0.266 \\
BHN & $400-425$ \\
Tensile strength Ultimate & $1272 \mathrm{MPa}$ \\
Tensile strength Yield & $1158 \mathrm{MPa}$ \\
Density & $0.00000785 \mathrm{Kg} / \mathrm{mm}^{3}$ \\
Behavior & Isotropic \\
\hline
\end{tabular}

Meshing has been done by properly selection of element type, relevance, refinement and sizing control. A meshed view of the model \& meshing details are shown in Fig. 7 and Table 3 below, respectively.

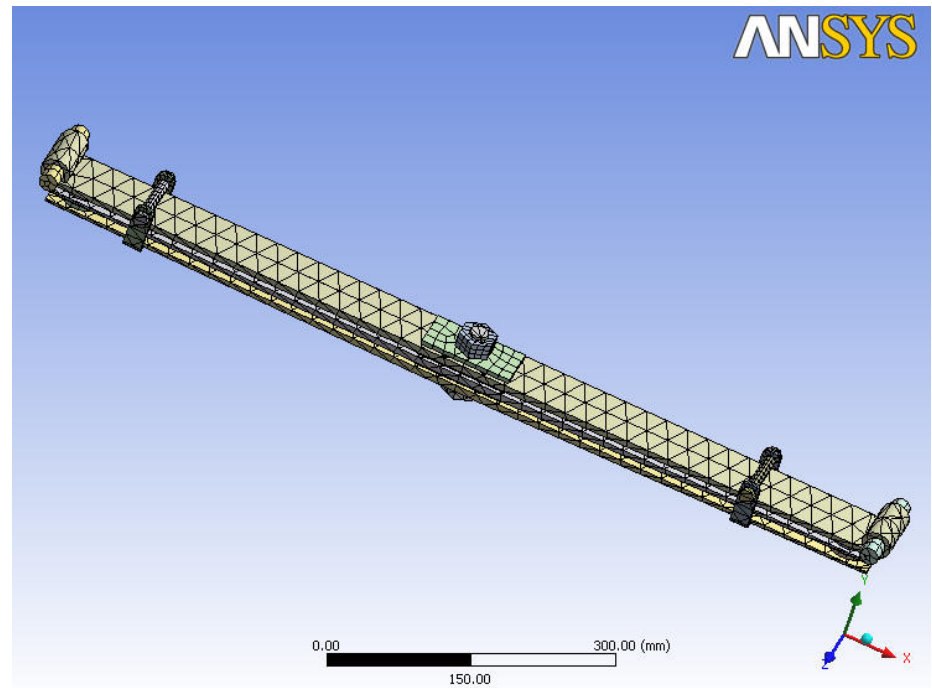

Fig. 7. Meshing of leaf spring assembly
Table 3

Meshing details in ANSYS-11 Report

\begin{tabular}{|c|c|}
\hline Object Name & Geometry \\
\hline State & Fully Defined \\
\hline \multicolumn{2}{|c|}{ Definition } \\
\hline Length Unit & Meters \\
\hline Element Control & Program Controlled \\
\hline Display Style & Part Color \\
\hline \multicolumn{2}{|c|}{ Bounding Box } \\
\hline Length X & 972. $\mathrm{mm}$ \\
\hline Length Y & 78. $\mathrm{mm}$ \\
\hline Length Z & $100.32 \mathrm{~mm}$ \\
\hline \multicolumn{2}{|c|}{ Properties } \\
\hline Volume & $1.1039 \mathrm{e}+006 \mathrm{~mm}^{3}$ \\
\hline Mass & $8.62 \mathrm{~kg}$ \\
\hline \multicolumn{2}{|c|}{ Statistics } \\
\hline Analysis Type & $3-\mathrm{D}$ \\
\hline Active Bodies & 24 \\
\hline Nodes & 14016 \\
\hline Elements & 4179 \\
\hline
\end{tabular}

These tip inserts are fixed on the upper face of leaf treated as bonded contact as shown in Fig. 8 while it is having no separation type of contact with the bottom face of upper leaf as shown in Fig. 9 to allow sliding motion between them. The boundary condition is the collection of different forces, pressure, velocity, supports, constraints and every condition required for complete analysis. Applying boundary condition is one of the most typical processes of analysis. A special care is required while assigning loads and constraints to the elements.

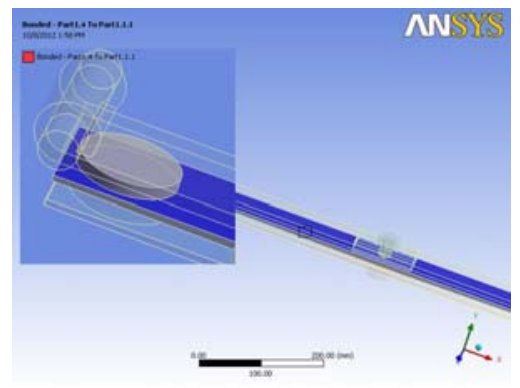

Fig. 8. Bonded Contact between leaf \& tip inserts

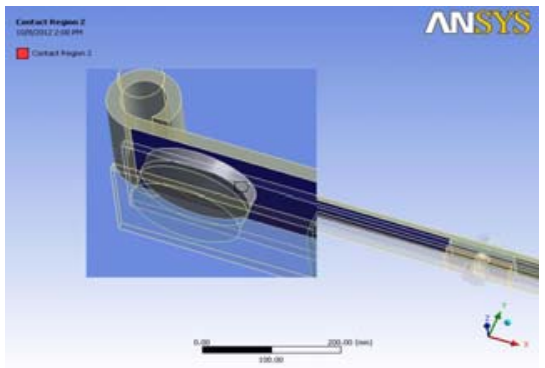

Fig. 9. No-Seperation Contact between leaf \& tip inserts

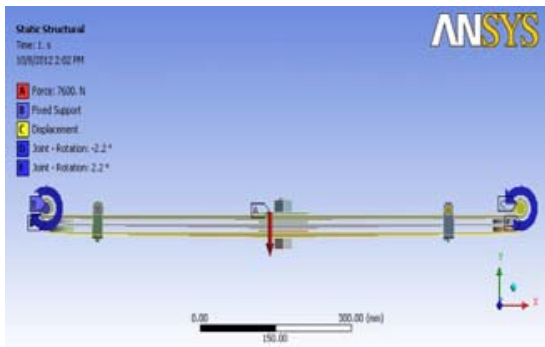

Fig. 10. Boundary conditions of parabolic leaf spring 
Boundary condition of the leaf spring involves the fixation of one of the revolute joint and applying displacement support at the other eye end of leaf spring. A joint rotation of $2.2^{\circ}$ has been taken for both revolute joints considering the no load camber. Loading conditions involves applying a load at the center of the leaf. As per specifications the spring is drawn at flat condition, therefore the load is applied in downward direction to achieve initial no load condition. The model under defined boundary conditions is shown in Fig. 10. The main leaf having two eye ends make revolute type of joint with pin inserted at both ends. Table 4 demonstrates the definition of both of the revolute joints. The details of load applied and different supports at both ends are defined in the Table 6.

\section{Table 4}

Revolute joint at eye ends between leaf and pin

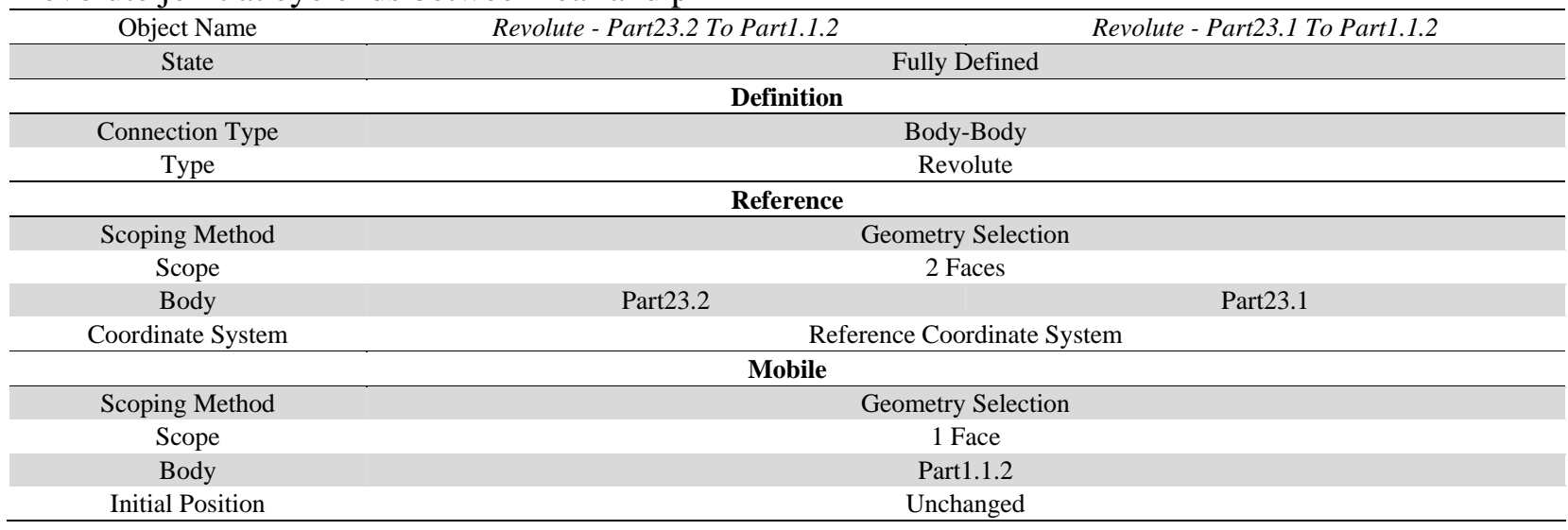

Table 5

Joint rotation at both revolute joints

\begin{tabular}{rccc}
\hline Joject Name & Joint - Rotation & Joint - Rotation \\
\hline State & Scope \\
\hline \multicolumn{4}{c}{ Fully Defined } \\
\hline Joint & Revolute - Part23.2 To Part1.1.2 & Revolute - Part23.1 To Part1.1.2 \\
\hline \multicolumn{3}{c}{ Definition } \\
DOF & Rotation Z \\
Type & Rotation & \\
Magnitude & $-2.2^{\circ}($ ramped $)$ & $2.2^{\circ}$ (ramped) \\
\hline
\end{tabular}

\section{Table 6}

Details of force \& supports applied

\begin{tabular}{rccc}
\hline Object Name & Force & Fixed Support & Displacement \\
\hline State & & Fully Defined & \\
\hline & & Scope & \\
\hline Scoping Method & Geometry Selection & 2 Faces \\
Geometry & 1 Face & Definition & Components \\
\hline Define By & Components & Fixed Support & Displacement \\
Type & Force & Global Coordinate System \\
Coordinate System & Global Coordinate System & Free \\
X Component & 0. N (ramped) & 0. mm (ramped) \\
Y Component & -7600. N (ramped) & & 0. mm (ramped)
\end{tabular}

\section{Results and Discussions}

As the FE Analysis of parabolic leaf springs has been done in the above section, and experimental results has been taken as the standards to compare with results obtained in the FE Analysis. Now it is necessary that we have some discussion on the both, experimental as well as FEA results and to reach for a conclusion. The result table of the FE analysis coming out of ANSYS-11 workbench is as under; 
Table 7

Results showing deformation \& equivalent stress

\begin{tabular}{|c|c|c|c|}
\hline Object Name & Total Deformation & Equivalent Stress & Directional Deformation \\
\hline State & \multicolumn{3}{|c|}{ Solved } \\
\hline \multicolumn{4}{|c|}{ Scope } \\
\hline Geometry & & All Bodies & \\
\hline \multicolumn{4}{|c|}{ Definition } \\
\hline Type & Total Deformation & Equivalent (Von-Mises) Stress & Directional Deformation \\
\hline Display Time & & End Time & \\
\hline Orientation & & & $\mathrm{X}$ Axis \\
\hline Coordinate System & & & Global Coordinate System \\
\hline \multicolumn{4}{|l|}{ Results } \\
\hline Minimum & $0 . \mathrm{mm}$ & $2.4617 \mathrm{e}-003 \mathrm{MPa}$ & $-10.116 \mathrm{~mm}$ \\
\hline Maximum & $56.806 \mathrm{~mm}$ & 1083.2 MPa & $3.8339 \mathrm{~mm}$ \\
\hline Minimum Occurs On & & $\operatorname{art} 23.2$ & Part1.2.6.5 \\
\hline Maximum Occurs On & Part1.3.6 & Part1.1.2 & Part1.2.6.6 \\
\hline
\end{tabular}

Linear static loading was performed in FEA to reduce the design complexity, material saving and time saving too.

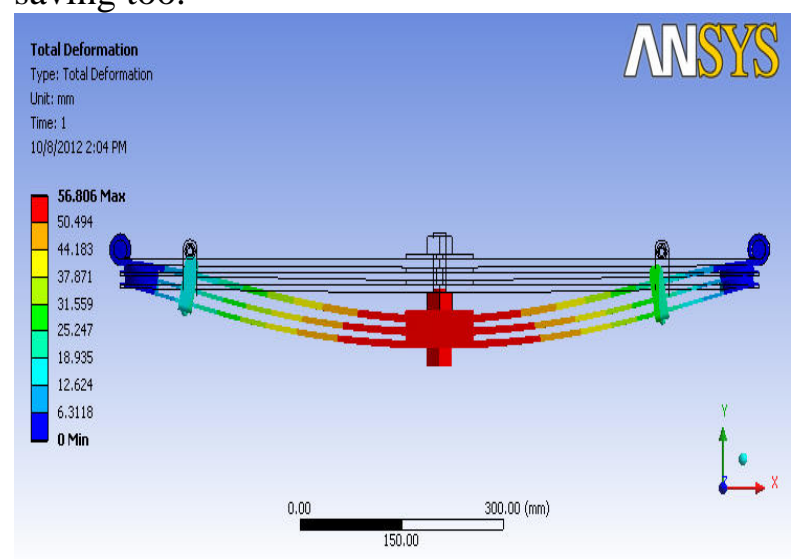

Fig. 11. Total deformation in the leaf spring

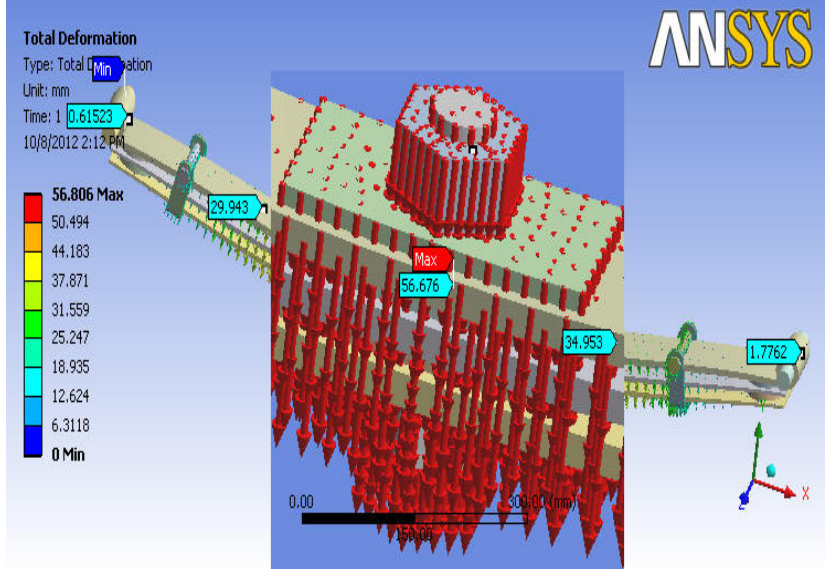

Fig. 12. Deformation vectors showing their intensity

As shown in above results the deflection and the von-mises stress are target results for comparison with the experimental results.

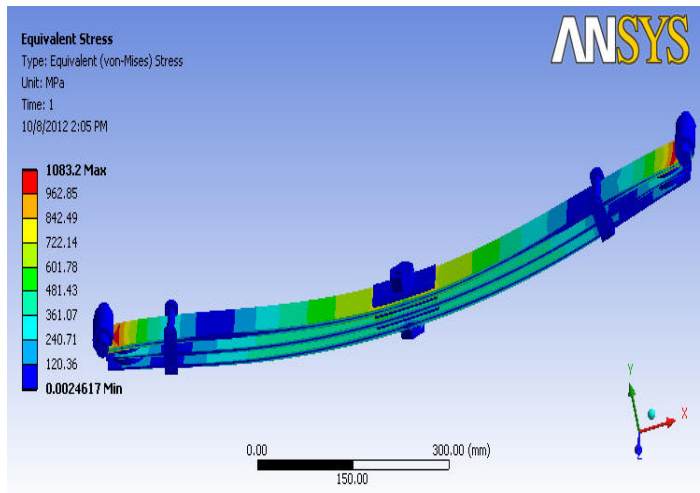

Fig. 13. Von-Mises stress contour

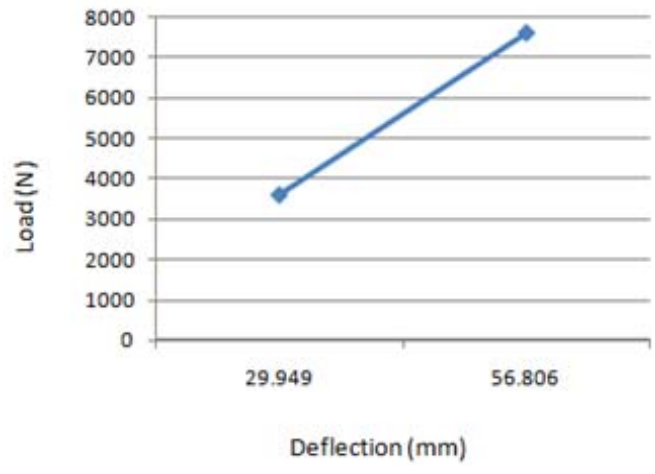

Fig. 13. Load-Deflection curve

The FEA deflection value is $56.806 \mathrm{~mm}$ having $16 \%$ deviation from experimental valuei.e. an acceptable deviation. On the other hand the equivalent von-mises stress is $1083.2 \mathrm{MPa}$ as obtained from computer aided finite element analysis through ANSYS. A stress deflection curve is plotted for 
rated load i.e. $3600 \mathrm{~N}$ and full load $7600 \mathrm{~N}$ as shown in Fig. 14, which is showing a straight line relation between stress and deflection.

\section{Conclusions}

A correlation of CAE Analysis with experimental results taken at industrial laboratory has been provided with this work. It is aimed to reach capability of manufacturing the right product at lower cost \& at one sitting instead of repeated design and prototype costs that made by trial and error methods. The result section above depict the total deflection as $56.806 \mathrm{~mm}$ in the parabolic leaf spring at full load i.e. the deflection obtained from FEA results are close to the experimental value. The corresponding equivalent von-misesstress developed in the leaf spring at same full load is $1083.2 \mathrm{MPa}$ i.e. the equivalent von-misesstress is observed to be well below the yield stress indicating that the design is safe. The parabolic leaf spring was found to weigh $8.05 \mathrm{Kg}$ recorded in the laboratory while FEA model of parabolic leaf spring weighs $8.62 \mathrm{Kg}$ i.e. a negligible difference between them. All these conclusions give very close results proving the validation of the FEA model as well as of this work.

\section{References}

Abdullah, S, Ahmad Refngah, F.N., Jalar, A., Chua, L.B., Ariffin, A.K., Zaharim, A. (2008). FEA - based durability assessment: A case study using a parabolic leaf spring, Proceedings of the 7th International Conference on System Science and Simulation in Engineering, WSEAS Press, ISSN:1790-2769, ISBN: 978-960-474-027-7, 67-72.

Aggarwal, M.L., \&Chawla, P.S. (2007).Issues in fretting fatigue design of shot peened leaf Springs. Indian Journal of Engineering Material Sciences,14, 414-418.

Aggarwal, M.L, Aggarwal, V.P., \& Khan R. A. (2006).A stress approach model for predictions of fatigue life by shot peening of EN45A spring steel, International Journal of Fatigue, 28, 1845-1853.

Aggarwal, M.L., Khan, R. A., \&Aggarwal, V.P. (2006).Effect of surface roughness on the fretting fatigue behaviour of EN45A spring steel.Journal of Engineering Manufacturing, 220, 1325-1331.

Ahmad Refngah, F.N., Abdullah, S., Jalar, A., \& Chua, L. B. (2009). Life assessment of a parabolic spring under cyclic strain loading,European Journal of Scientific Research, 28(3), 351-363.

Dewangan, R.K., Patnaik, M., \&Yadav, N. (2012).Minimization of stress of a parabolic leaf spring by simulated annealing algorithm, International Journal of Engineering research and Applications, 2(4), 457-460.

Gokhale, N.S. (2008). Practical Finite Element Analysis, Finite to Infinite. Pune.

Jayaswal, P., \&Kushwah, A.S. (2012).Rejection minimization in parabolic leaf spring manufacturing unit in India, International Journal of Applied Research in Mechanical Engineering, 2(1), 70-75.

Kanbolat, A., \&Soner, M.(2011). Load Simulation and Analysis in Automotive Engineering, SAE International Publisher. U.S.

Patnaik, M., Koushik, L.P., \& Mathew, M. (2012a).Determination of camber and leaf span of a parabolic leaf spring for optimized stress and displacement using artificial neural networks, International Journal of Modern Engineering Research, 2(4), 2771-2773.

Patnaik, M., Yadav, N., \&Dewangan, R. (2012b). Study of a parabolic leaf spring by finite element method \& design of experiments, International Journal of Modern Engineering Research, 2 (4), 1920-1922.

SAE HS-788 (1980).Manual on Design and application of leaf spring, SAE HS-788.

Soner, M., Guven, N., Kanbolat, A., Erdogus, T., \&Karaagac, M. (2011). Parabolic leaf spring design optimization considering FEA \& rig test correlation, Commercial Vehicle Engineering Congress, Chicago, SAE International, Paper Number: 2011-01-2167, doi: 10.4271/2011-01-2167

Yadav, N., Dewangan, R., \&Patnaik, M. (2012).Minimization of stress in a parabolic leaf spring by local algorithm for constant \& priorities.International Journal of Engineering Research and Applications, 2(4), 1897-1899

Tikoo, S., Maini, D., \&Raina, V. (Reprint 2007), CATIA V5R16 for Engineers \& Designers, Dreamtech Publisher, New Delhi. 